Valor del acuerdo transaccional de una partición en relación a un laudo arbitral

y los honorarios fijados por el árbitro.

María Fernanda Vásquez Palma

páginas $343-352$

\title{
VALOR DEL ACUERDO TRANSACCIONAL DE UNA PARTICIÓN EN RELACIÓN A UN LAUDO ARBITRAL Y LOS HONORARIOS FIJADOS POR EL ÁRBITRO.
}

\author{
María Fernanda Vásquez Palma*
}

\section{Presentación del tema.}

$\mathrm{El}$ art. 227 del COT plantea varios casos de arbitraje forzoso, lo que trasunta necesariamente en la negación de la autonomía de la voluntad de las partes en este campo, en cuanto a decidir llevar el litigio que les ocupa ante la justicia ordinaria, desfigurando la esencia misma de la institución arbitral que descansa precisamente sobre el pilar de la libertad de las partes. Esta obligatoriedad tiene una excepción, en cuanto esta misma disposición en su inciso tercero, faculta a los interesados (entiéndase partes del litigio) a resolver por sí mismos estos negocios, si todos ellos tienen la libre disposición de sus bienes y concurren al acto, sin perjuicio de lo dispuesto en el artículo 645 del CPC . Como se comprenderá, esta norma implica que las partes pueden solucionar sus diferencias por sí mismos si están de común acuerdo, con lo que el forzamiento al arbitraje deja de ser tal. Esto implica que el legislador deja una puerta semiabierta a la voluntad de las partes en cuanto se les permite terminar sus litigios de una manera distinta a la arbitral, como por ejemplo, por medio de los acuerdos transaccionales, pero de ninguna manera se les reconoce u otorga el derecho de recurrir a los tribunales ordinarios.

Bajo esta lógica, en el caso concreto de la partición de bienes hereditarios el legislador contempla una norma especial. Se trata del art. 1325 del CC que permite que los consignatarios puedan realizar por sí mismos la partición, si todos ellos están de acuerdo en la manera de realizar la división, concurren al acto - aunque entre ellos haya personas que no tengan la libre

* Profesora de Derecho Comercial, Facultad de Ciencias Jurídicas y Sociales de la Universidad de Talca. Doctora en Derecho por la Universidad Complutense de Madrid. Magíster en Derecho Privado por la Universidad de Talca. Correo electrónico: $\underline{\text { mfvasquez@utalca.cl }}$ 
disposición de sus bienes-, y siempre que no se presenten cuestiones que resolver, con lo que la excepción en comento plantea cierta novedad.

Las normas en comento no clarifican cuándo las partes podrían ejercer tal facultad, de manera que podrá ocurrir que se de inicio al juicio arbitral y el ínterin, es decir, antes que éste concluya, las partes decidan poner término a su conflicto por medio un acuerdo o transacción extrajudicial. ¿Qué efectos tiene esta decisión sobre el arbitraje? Es la interrogante que se intentará responder en las siguientes líneas al analizar una de las pocas y recientes sentencias dictada sobre esta materia.

\section{Explicación de caso.}

En causa caratulada "Dodds Rosas, Cristián c/ Hott Ehrenfeld, Eduardo", Rol No 204608, la Excma. CS dictó recientemente una sentencia (11 de junio de 2009), que en lo medular expone:

"Corresponde acoger la demanda que pretende el cumplimiento de lo fijado por el árbitro en el laudo y rechazar el recurso de casación interpuesto por uno de los interesados en la partición en contra de al sentencia definitiva de segunda instancia, toda vez que los comuneros alcanzaron un acuerdo transaccional plasmado en escritura pública donde se dio cuenta de haber puesto término a la cuestión del juicio particional, y establecieron al efecto que procederían a practicarla convencionalmente, que los bienes a considerar serían los consignados en la ordenata y que la tasación de éstos sería convenida de manera libre por los intervinientes, pues lo desarrollado en el juicio particional no contó con el concurso del juez árbitro, en consecuencia, no le empece lo acordado en el juicio particional siéndole dichos acuerdos inoponibles.

La transacción utilizada por los partícipes para poner término al estado de indivisión, posee pleno valor y fuerza las estipulaciones que allí se consignaron, pero sólo para quienes concurrieron con su voluntad suscribir dicho contrato. Lo que no aconteció en la especie, en la que existiendo un juicio arbitral, el árbitro no tomó parte y sus honorarios no fueron propuestos al tiempo de dictar la sentencia arbitral, sino que convenidos entre los intervinientes del proceso divisorio y el mismo árbitro, al tiempo de iniciar el juicio particional y en donde la cuantía estaba determinada por un porcentaje -primer elemento de la fórmula- y la masa hereditaria partible -segundo elemento de la fórmula- esta última resultante de las operaciones y cálculos contenidos en la ordenata.

Cuando en la especie se arribó a una solución por medio de una transacción, pero que no contó con el concurso del juez árbitro y, sin embargo, se pretende por la demandada hacer oponible a aquél todas y cada una de las cuestiones allí acordadas entre los interesados, entre ellas y en rigor en lo que interesa, un determinado valor de la masa hereditaria que resulta muy inferior al establecido por el árbitro al tiempo de dictar su sentencia, para lo cual fue requerida su competencia profesional, corresponde entender 
Valor del acuerdo transaccional de una partición en relación a un laudo arbitral

y los honorarios fijados por el árbitro.

que la transacción posee fuerza entre los partícipes sin menoscabar la sentencia del juicio particional".

Si bien el fallo no explica de manera pormenorizada cada uno de los hechos, es posible apreciar que en el caso en cuestión se dio precisamente la combinación de ambas circunstancias, esto es, por un lado, las partes iniciaron un juicio arbitral y, antes que se dictara sentencia en el mismo, acordaron suscribir un acuerdo transaccional; no obstante, el juicio arbitral continuó tramitándose hasta la dictación de su respectivo laudo. Derivado de ello, el árbitro solicitó el cumplimiento de la sentencia, demanda que fue rechazada en primera instancia, pero acogida por la CA de Valdivia en segunda instancia. En contra de esta última sentencia se opuso un recurso de casación en la forma y en el fondo declarándose inadmisible el primero de ellos.

En relación a éste último recurso, la Excma. CS consideró para resolver que: 1. Se denuncian infringidos los artículos 2446 inc. $1^{\circ}$ y el art. 2460 del CC, al permitir el fallo impugnado el cumplimiento incidental del laudo y la ordenata; así como también el art. 1545 del mismo cuerpo legal, al restársele mérito a la transacción lograda por las partes para determinar el monto de la masa hereditaria; 2. Que las partes argumentan que la tesis de la sentencia impugnada es errada pues reconoce al laudo arbitral como título para su ejecución, en circunstancias que el litigio terminó antes por medio de transacción. De este modo, de reconocerse valor a la sentencia se está admitiendo que existen dos modos para terminar el litigio, cuestión que evidentemente no es posible, pues sólo la transacción ostenta tal valor; 3 . Asimismo, existe una falta de legitimación activa de parte del árbitro, pues sólo las partes están legitimadas para solicitar el cumplimiento incidental del laudo, y no aquél. En tal sentido, es insostenible que quien dicta la resolución pida su cumplimiento frente a las partes; 4. Finalmente, se arguye que aún cuando se admita que la sentencia arbitral produce efectos, claramente el monto asignado a los honorarios infringe la norma del art. 1545 al restarle fuerza obligatoria a la transacción. No puede sostenerse - en opinión del recurrente- que la sentencia arbitral sea vinculante para las partes respecto de la masa partible sólo en cuanto a los honorarios del partidor y que no lo sea en cuanto a sus relaciones recíprocas.

En cuanto a los hechos, se expresa que efectivamente las partes alcanzaron una transacción en mayo de 2005. En dicho instrumento los interesados dieron cuenta de haber puesto término total y definitivo a sus diferencias respecto de la partición en cuestión, con expresa mención del juicio particional, y establecieron al efecto que procederían a practicarla convencionalmente, que los bienes a considerar serían los consignados en la ordenata y, que la tasación de los mismos sería convenida de manera libre por los intervinientes. Conforme a ello se estableció en la escritura pública de partición que el monto del acervo líquido partible ascendía a $\$ 1.833 .502 .833$, cantidad inferior a la suma de $\$ 4.054 .606 .098$ consignada en la ordenata.

A raíz de ello, los jueces de la Exma. Corte razonan en el sentido que la transacción no contó con el concurso del árbitro y que sin embargo se pretende por las partes hacer oponible 
a aquél todas y cada una de las cuestiones allí acordadas entre los interesados, entre ellas y en rigor en lo que interesa, un determinado valor de la masa hereditaria que resulta muy inferior al establecido por el árbitro al tiempo de dictar su sentencia para lo cual fue requerida su competencia profesional. Lo anterior - continúan los sentenciadores-, no quita fuerza a la transacción como fórmula utilizada por los partícipes para poner término al estado de indivisión, siendo de pleno valor y fuerza las estipulaciones que allí se consignaron, pero sólo para quienes concurrieron con su voluntad a suscribir dicho contrato, cuyo no fue el caso del mencionado árbitro, por cuanto sus honorarios no fueron propuestos al tiempo de dictar la sentencia arbitral, sino que convenidos, esto es, acordados entre los intervinientes del proceso divisorio y el mismo árbitro al tiempo de iniciar el juicio particional.

Esgrimen que al iniciar el juicio particional, las partes junto al árbitro convinieron que los honorarios de éste último se fijarían en base a dos criterios: 1 . un porcentaje de la masa hereditaria (10\%), y 2. La masa hereditaria partible que resulte de las operaciones y cálculos contemplados en la ordenata. De tal manera que si se le resta validez al laudo, ello implicaría la instrumentalización del contrato por parte de unos, en perjuicio de otros, cuestión que repudia el principio de buena fe. En base a ello, se procedió a rechazar el recurso de casación en el fondo.

\section{Análisis del caso.}

El fallo en cuestión plantea numerosas interrogantes: ¿Podría el árbitro concurrir con su voluntad a la transacción?; ¿Podría seguirse substanciando el juicio arbitral existiendo una transacción de por medio?; ¿Podría concederse valor sólo a una parte del laudo y negársele al resto? Éstas y otras intentaremos responder en las siguientes líneas.

En primer lugar, no podemos dejar de hacer presente que la sentencia en comento se presenta a ratos ciertamente confusa, por ejemplo, señala que el juez árbitro no concurrió al juicio particional, en circunstancias que lo quiso decir es que no concurrió a la transacción celebrada por las partes; empero, más allá de estos incomprensibles errores de forma, nos interesan principalmente los razonamientos arribados en relación al contenido de la misma. En tal escenario, debemos precisar que el asunto debatido liga con diversas variables, a saber:

1. El valor del acuerdo transaccional.

2. El valor de la sentencia dictada por el árbitro.

3. El valor del acuerdo de honorarios alcanzados entre las partes y el árbitro.

4. Vías legales que debieron considerarse para resolver el conflicto suscitado.

Como punto de partida entendemos que los interesados hicieron uso de su legítimo derecho a llegar a un acuerdo transaccional para poner término a su litigio y así no continuar el juicio arbitral que, sin mediar tal circunstancia, sería forzoso. Se desprende del fallo en análisis que 
Valor del acuerdo transaccional de una partición en relación a un laudo arbitral

y los honorarios fijados por el árbitro.

el respectivo acuerdo transaccional se hizo presente en el juicio arbitral y que no se puso en duda la validez del mismo en momento alguno. De hecho, lo que cuestionó el sentenciador fue más bien el efecto que tal contrato tenía respecto del árbitro, señalando que ningún valor podría tener en relación a éste último porque no concurrió al mismo, de manera que más que esgrimir la nulidad de la transacción, aduce la inoponibilidad como sanción.

El fallo, por tanto, esgrime como base de su resolución que la transacción debiera haber contado con el concurso del juez árbitro. Nosotros no concordamos con tal análisis, ni menos aún con la aludida afirmación, por estimarla plenamente errada. En efecto, según ya revisamos, los Arts. 227 del COT y 1325 del CC posibilitan que los interesados puedan resolver por sí mismos sus litigios o negocios que, en otras circunstancias, debieran llevarse a un arbitraje forzoso. Al emplearse el vocablo "interesados" o "coasignatarios", respectivamente, el legislador se está refiriendo a las partes afectadas por el litigio, de manera que no exige la concurrencia del árbitro (si éste ya estaba conociendo de un juicio arbitral), bajo ningún supuesto. A idéntica conclusión arribamos de lo dispuesto en los Arts. 2446 y 2461 del CC y la lectura de la frase "resolver por sí mismos" acuñada en el Art. 227 en comento, toda vez que con ello se plantea derechamente el mecanismo de la autocomposición, lo que equivale a descartar la figura del árbitro en tal acuerdo en cuanto se trata de un derecho que se ejerce dentro de la esfera de lo privado y sin el ministerio o autorización de otro.

Desde otra óptica, debemos reparar en el hecho que las partes no modificaron en su transacción - a lo menos de manera directa- el contrato de honorarios que suscribieron con el árbitro, por lo que no se requería de su concurso o consentimiento de manera alguna. La determinación de la masa partible y su cuantificación constituían un requisito sine qua non de la correspondiente transacción, pues es sobre esta base que se efectúan las correspondientes adjudicaciones y divisiones. Si tal estimación afectaba el contrato de honorarios en referencia, ello debió ser alegado por el árbitro por medio de los mecanismos correspondientes.

Si la transacción es válida, habrá que entender que las partes dieron cumplimiento a lo pactado en el inc. $2^{\circ}$ del art. 1325 , es decir, procedieron a tasar los bienes comprometidos en la partición por medio de peritos, para posteriormente requerir la aprobación de la misma por la justicia ordinaria, de manera que a priori no se podría entender el argumento sobre el que descansa la sentencia, en el sentido que imprime al acuerdo transaccional un sentido claramente instrumentalizador de querer lesionar los intereses económicos del árbitro, en relación a sus honorarios.

Afirmándose tan claramente tal validez, ¿puede tener algún alcance o efecto el laudo dictado por el árbitro? Pues bien, aún cuando el sentenciador estima que la transacción tiene pleno valor entre las partes, a diferencia de la ordenata, tal conclusión no se formula en términos concluyentes pues aduce que, si bien en términos generales ésta última no tiene ningún valor para aquéllas, si lo tiene en lo relativo a la fijación de la masa partible de la cual se derivan los honorarios de los árbitros. 
He aquí donde los postulados judiciales nuevamente se tornan espinosos, pues la interrogante que necesariamente aflora es la siguiente: ¿Es posible conferir valor a una sentencia arbitral sólo en lo relativo a un punto? El sentenciador justifica su decisión en la posible instrumentalización que podría sufrir el Derecho si las partes, por medio de un acuerdo privado, perjudican los intereses de terceros (como ocurriría con los honorarios del árbitro). Como finalidad loable nadie pudiera discutir este punto, no obstante, lo cierto es que no se reparan en algo substancial, como es el hecho que si existe una transacción válida la sentencia arbitral necesariamente será nula en todas sus partes por carecer completamente de asidero y justificación, en tanto carece de causa y objeto (no existía ya el conflicto). En efecto, la existencia de esta transacción implica reconocer necesariamente que ha operado un equivalente jurisdiccional, de manera que el juicio arbitral no pudo seguir sustanciándose una vez que ella fue suscrita, pues puso total término a los conflictos que originaron el arbitraje respectivo.

En otras palabras, el punto que intenta salvar la Excma. Corte Suprema tiene una única vertiente y fundamento como es la protección de la fuerza obligacional del contrato de honorarios pactados entre el árbitro y las partes, es decir, de un contrato enteramente privado. Ciertamente los honorarios del árbitro fueron pactados al inicio del juicio arbitral de una manera incierta, pues se estimaron sobre la base de un cálculo y hecho futuro, en tal sentido, se estipuló que le corresponderían el $10 \%$ de la masa partible que se determinara en la ordenata. Para ello debía considerarse que los honorarios estaban fijados en base a ciertos hechos, y desde esta óptica podría comprenderse que se trataba de una obligación sujeta a condición, es decir, las partes pagarían el porcentaje acordado de la masa partible que se determinara en la ordenata si se llegaba obviamente a este punto en el juicio arbitral. Si el árbitro hubiese fallecido justo antes de dictar el correspondiente laudo, habiendo efectuado buena parte de su labor, las partes no podrían haber esgrimidos a los herederos de aquél que los honorarios son improcedentes porque no llegó a dictarse la correspondiente sentencia arbitral.

Desde esta lógica, es evidente que las partes asumieron una obligación que no pueden soslayar ni aún sobre la base de una transacción, pues los honorarios del árbitro debían satisfacerse en base al trabajo desplegado, no obstante ello ¿podría sostenerse que sólo para cumplir esta obligación se vulneren normas de orden público, como ocurre al conferir valor a una sentencia arbitral posterior a un acuerdo transaccional válidamente pactado, y se permita así al juez árbitro exigir incidentalmente el cumplimiento de la sentencia por él dictada? Por supuesto que no.

En mi opinión, este planteamiento sólo podría explicarse bajo la lógica de comprender que la fijación de honorarios que puede realizar el árbitro en su sentencia (a que alude el art. 665 del CPC) no forma parte de la misma y debe, por tanto, entenderse como una propuesta completamente aislada. En otras palabras, se deben entender que los honorarios resultan siempre de una relación obligacional habida entre las partes y el árbitro, y la fijación de éstos en la 
Valor del acuerdo transaccional de una partición en relación a un laudo arbitral

y los honorarios fijados por el árbitro.

sentencia no modifica tal naturaleza, de manera que no puede concluirse que aquéllos formen parte integrante de la misma. Entenderlo de una forma contraria desnaturalizaría la función básica de toda resolución que es precisamente "resolver un conflicto".

No hay duda al respecto, la fijación de los honorarios que se efectúa en la sentencia no importa parte de la misma, ni una resolución, sino más bien la proposición de los mismos a las partes involucradas en el litigio a partir de una atribución legal o convencional conferida anticipadamente. Si la determinación que efectúa el árbitro y ello tiene fuerza obligatoria para las partes, no lo es porque constituya una resolución judicial, sino porque importa una expresión del acuerdo que ellas mismas suscribieron por adelantado con el árbitro.

En la ilación de este razonamiento se comprenderá que la diferenciación apuntada no es baladí, ni superflua, pues ello trasciende en el cumplimiento de lo señalado en la respectiva sentencia y la fijación de honorarios, en tanto tendrán necesariamente un tratamiento diverso: por una parte el de la sentencia arbitral propiamente tal que debe seguir lo preceptuado en el CPC para estos efectos, y por otro, el de la fijación de honorarios, en que el árbitro - que es el interesado en su cumplimiento- deberá formular por las vías procesales que para el caso están establecidas, es decir, el cobro de honorarios. Así, el árbitro que se sintió lesionado por la transacción celebrada por las partes debió proceder al cobro o reclamo de sus honorarios por las vías correspondientes, en razón de las gestiones hasta ese momento realizadas (en el entendido que si bien inició el juicio arbitral, no lo concluyo por una causa ajena a su voluntad, como fue el ejercicio del derecho conferido a las partes legalmente) .

En resumen, aún cuando el sentenciador intentara salvar el acuerdo de honorarios pactado entre las partes y el árbitro, no pudo -como en definitiva llegó a hacerlo- admitir que el árbitro intente o solicite el cumplimiento de la sentencia arbitral para los efectos de su cobro de honorarios, por cuanto: a. El no estaba legitimado para solicitar tal cumplimiento, sólo las partes podrían hacerlo; b. la Fijación de honorarios no forma parte de la sentencia arbitral propiamente tal, su cumplimiento debía formularse por las vías procesales correspondientes; y c. La sentencia arbitral era nula por haber operado previamente un equivalente jurisdiccional.

De esta manera, el asunto que desencadenó este entramado jurídico, no fue más que un contrato de honorarios mal estipulado, por cuanto aquél debió haber previsto la posibilidad de ocurrencia de circunstancias excepcionales, tales como, el posible fallecimiento del árbitro, su inhabilidad posterior, la llegada de un acuerdo extrajudicial, etc.; pero ello no justifica en modo alguno el fallo que acabamos de exponer en cuanto con él se destruye buena parte de nuestras instituciones fundamentales y de orden público. La exposición de este fallo pretende reparar en estos hechos con el afán de explicar esta temática e intentar que un fallo de esta naturaleza no tenga eco en nuestro estadio jurídico. 


\section{Anexo: Transcripción de la sentencia.}

Santiago, 11 de junio de 2009.

Vistos:

En estos autos Rol N 253-2006.- del Primer Juzgado Civil de Osorno sobre cumplimiento incidental, caratulados «Dodds Rosas, Cristián con Hott Ehrenfeld, Eduardo», por sentencia de 9/11/2007, escrita a fojas 22, el señor Juez Subrogante del referido tribunal rechazó la demanda interpuesta. Apelado este fallo por el demandante, una de las Salas de la Corte de Apelaciones de Valdivia, en sentencia de 18/3/2008, que se lee a fojas 43, lo revocó y declaró en su lugar que la demanda queda acogida.

En contra de esta última decisión el demandado dedujo recursos de casación en la forma y en el fondo, declarándose inadmisible el primero por resolución de 26/6/2008, rolante a fojas 67

Se ordenó traer los autos en relación para conocer del recurso de casación en el fondo: Considerando:

Primero: Que en el recurso de casación en el fondo se denuncian infringidos los artículos 2446 inciso $1^{\circ}$ y 2460 del Código Civil -al permitir el fallo impugnado el cumplimiento incidental del laudo y la ordenata- y el artículo 1545 del mismo cuerpo legal -al restársele mérito y eficacia a la transacción lograda por las partes para determinar el monto de la masa hereditaria. En cuanto a la vulneración del primero de los preceptos mencionados, se argumenta en el recurso que no es jurídicamente correcta la tesis de la sentencia, en orden a que la transacción tendría pleno valor entre las partes, dado que está reconociendo al laudo y ordenata un efecto legal que no tiene, cual es servir de título para su ejecución. En consecuencia, sigue el recurrente, una vez celebrada la transacción el juicio particional terminó definitivamente y, por ende, no es sostenible que se pretenda dar cumplimiento a un laudo y ordenata que no ha tenido el mérito ni la virtud de finalizar el pleito. Si existe un instrumento que tiene fuerza y mérito ejecutivo, concluye, es la transacción que constituyó la única forma con que se puso fin al juicio.

En relación al artículo 2460 del Código Civil el recurrente expone que es un hecho indubitado que la transacción puso término al pleito y que, por consiguiente, la sentencia dictada por el árbitro no ha tenido incidencia alguna en él. Es contradictorio, agrega, que un juicio pueda terminar, conjuntamente y sobre la base de idénticos derechos, mediante una transacción y una sentencia definitiva; por lo tanto, debe concluirse que el laudo y la ordenata no tienen jurídicamente ningún valor. La sentencia, se afirma en el recurso, infringe el precepto citado, en la medida que desconoce la fuerza de cosa juzgada de la transacción.

De igual forma, continúa el recurrente, ha pasado inadvertida la evidente falta de legitimación activa del actor, pues no puede el partidor pretender pedir en vía ordinaria el cumplimiento del fallo que dicta, por cuanto esta facultad -que importa el ejercicio de la acción de cosa juzgada- corresponde a las partes y no al juez. Es jurídicamente insostenible, finaliza, que el mismo tribunal que dicta una resolución pida su cumplimiento frente a las partes. 
Valor del acuerdo transaccional de una partición en relación a un laudo arbitral

y los honorarios fijados por el árbitro.

Por último, en lo que a la contravención del artículo 1545 del Código Civil se refiere, el recurrente expresa que aún cuando se admita que la sentencia arbitral produce efectos, claramente el monto asignado a los honorarios infringe la norma citada (sic), al restarle fuerza obligatoria a la transacción.

En virtud del principio de la autonomía de la voluntad y tal como lo indica la sentencia, se explica en el recurso, para determinar el monto de los honorarios se fijó una fórmula compleja: por un lado un porcentaje (10\%) y, por otro, una base para aplicarlo (la valoración de la masa partible). Lo que efectivamente se hace en la transacción, añade la parte recurrente, es fijar una masa partible inferior a la determinada en el fallo arbitral, lo que sin lugar a dudas no modifica el pacto de honorarios. Por lo mismo, tal operación es plenamente válida y está dentro de los actos que corresponden a la esencia del contrato de transacción (el partidor debió prever la posibilidad, al concurrir con su voluntad a la fijación de la fórmula, que el juicio terminara en virtud de un equivalente jurisdiccional).

No puede sostenerse, finaliza el recurso, que la sentencia arbitral sea vinculante para las partes respecto de la masa partible sólo en cuanto a los honorarios del partidor y que no lo sea en cuanto a sus relaciones recíprocas

Segundo: Que el fallo impugnado establece que previo a resolver el recurso de casación interpuesto por uno de los interesados en la partición en contra de la sentencia definitiva de segunda instancia, los comuneros alcanzaron un acuerdo que plasmaron bajo la fórmula de una transacción, suscrita por escritura pública de 4/5/2005. En este instrumento, siguen los magistrados, los interesados dieron cuenta de haber puesto término total y definitivo a sus diferencias respeto de la partición en cuestión, con expresa mención, precisamente, al juicio particional, y establecieron al efecto que procederían a practicarla convencionalmente, que los bienes a considerar serían los consignados en la ordenata y, por último, que la tasación de éstos sería convenida de manera libre por los intervinientes. Conforme a lo anterior, agregan, la escritura pública de partición estableció que el monto del acervo líquido partible ascendía a $\$ 1.833 .502 .833$.-, cantidad muy por debajo de la suma de $\$ 4.054 .606 .098$.- consignada en la ordenata. Como puede apreciarse, razonan los jueces, la transacción no contó con el concurso del juez árbitro y, sin embargo, se pretende por la demandada hacer oponible a aquél todas y cada una de las cuestiones allí acordadas entre los interesados, entre ellas y en rigor en lo que interesa, un determinado valor de la masa hereditaria que resulta muy inferior al establecido por el árbitro al tiempo de dictar su sentencia, para lo cual fue requerida su competencia profesional. Lo anterior, sigue el raciocinio, no quita fuerza a la transacción como fórmula utilizada por los partícipes para poner término al estado de indivisión, siendo de pleno valor y fuerza las estipulaciones que allí se consignaron, pero sólo para quienes concurrieron con su voluntad a suscribir dicho contrato, cuyo no fue el caso del mencionado árbitro, por cuanto sus honorarios no fueron propuestos al tiempo de dictar la sentencia arbitral, sino que convenidos, esto es, acordados entre los intervinientes del proceso divisorio y el mismo árbitro, al tiempo de iniciar el juicio particional y en donde la cuantía estaba determinada por un porcentaje primer elemento de la fórmula- y la masa hereditaria partible -segundo elemento de la fórmula, esta última resultante de las operaciones y cálculos contenidos en la ordenata. 
Razonar en sentido contrario, concluye el fallo, es desconocer que en lo referido a honorarios los interesados en la partición son contraparte del árbitro, desde que éste determinó ciertos valores al tiempo de emitir su decisión, por lo que cualquier modificación al respecto que no viniese por vía jurisdiccional, como aquí ocurrió, demanda necesariamente la participación del árbitro. Sostener lo contrario, finaliza, implicaría admitir la instrumentalización de un contrato por parte de unos en perjuicio de otros, cuestión que repudia al principio de la buena fe.

Tercero: Que para un adecuado análisis de las normas denunciadas como infringidas por el recurrente, corresponde en primer término pronunciarse respecto del primer error de derecho que se atribuye a la sentencia contenida en el motivo primero que antecede, que consiste en la vulneración del artículo 2446 inciso $1^{\circ}$ del Código Civil que prescribe «la transacción es un contrato en que las partes terminan extrajudicialmente un litigio pendiente, o precaven un litigio eventual». Esta norma contiene sólo un concepto legal de transacción y, en consecuencia, no puede haber infracción de esta disposición, si no se denuncia vulnerada, respecto de las partes, alguna condición de validez que le reste valor.

Cuarto: Que en cuanto al segundo error de derecho que se atribuye en la casación de fondo a la sentencia dictada en el proceso referida al artículo 2460 del Código Civil, dicha sentencia no menciona el artículo citado por lo que no puede infringirse. Los jueces de fondo en su fallo aplicaron el artículo 2461 inciso primero, norma no señalada por el recurrente, al establecer que la transacción alcanzada por los herederos de don Eduardo Hott Ehrenfeld, para poner término al estado de indivisión, tiene pleno valor y fuerza sólo entre las partes intervinientes. Y que el desarrollo del juicio particional no contó con el concurso del juez árbitro, en consecuencia, no le empece lo acordado en el juicio particional siéndole dichos acuerdos inoponibles.

Quinto: Que en lo relativo al tercer error de derecho denunciado en el recurso referido a la contravención del artículo 1545 del Código Civil. Del análisis efectuado se puede concluir que los jueces de la instancia aplicaron bien la ley puesto han reconocido la fuerza obligatoria del contrato de transacción para los coherederos que concurrieron al juicio particional, pero no permitiendo que sus efectos perjudiquen al juez árbitro quién no participó en ella.

Sexto: Que, en consecuencia, al no haberse incurrido en las infracciones de ley denunciadas en el recurso, no cabe sino concluir que la casación de fondo intentada debe ser necesariamente desestimada.

Por estas consideraciones y visto, además, lo dispuesto en las normas legales citadas y en los artículos 764, 75, 767 y 805 del Código de Procedimiento Civil, se rechaza el recurso de casación en el fondo deducido por la parte demandada en el primer otrosí de la presentación de fojas 46, contra la sentencia de 18/3/2008, escrita a fojas 43 .

Regístrese y devuélvase, con sus agregados.

Redacción de la abogada integrante señora Maricruz Gómez de la Torre. $\mathrm{N}^{\circ} 2046-08$.

Pronunciado por la Primera Sala de la Corte Suprema, por los Ministros Sres. Milton Juica A., Sergio Muñoz G. y Juan Araya E. y Abogados Integrantes Sr. Jorge Medina C. y Sra. Maricruz Gómez de la Torre V. 